\title{
Hydration characteristics and structure formation of cement pastes containing metakaolin
}

\author{
Leonid Dvorkin ${ }^{1}$, Nataliya Lushnikova ${ }^{2}$, Oleksandr Bezusyak ${ }^{1}$, Mohammed Sonebi ${ }^{3}$ and Jamal Khatib ${ }^{4,5}$ \\ ${ }^{1}$ National University of Water and Environmental Engineering, Department of Building Products Technology and Materials \\ Science, Rivne, Ukraine \\ ${ }^{2}$ National University of Water and Environmental Engineering, Department of Architecture and Environmental Design, \\ Rivne, Ukraine \\ ${ }^{3}$ School of Natural and Built Environment, Queen's University Belfast, Belfast, Northern Ireland, UK \\ ${ }^{4}$ Faculty of Engineering, Beirut Arab University, Beirut, Lebanon \\ ${ }^{5}$ Faculty of Science and Engineering, University of Wolverhampton, Wolverhampton, UK
}

\begin{abstract}
Metakaolin (MK) is one of the most effective mineral admixtures for cement-based composites. The deposits of kaolin clays are wide-spread in the world. Metakaolin is comparable to silica fume as an active mineral admixture for cement-based composites. In this paper, the rheological and mechanical properties of cement paste containing metakaolin are investigated. The effect of MK is more evident at "tight" hydration conditions within mixtures with low water-cement ratio, provided by application of superplasticizers. The cement is replaced with 0 to $15 \%$ metakaolin, and superplasticizer content ranged from 0 to $1.5 \%$ by weight of cementitious materials (i.e. cement and metakaolin). An equation is derived to describe the relationship between the metakaolin and superplasticizer content and consistency of pastes. There is a linear dependence between metakalolin content and water demand. Second-degree polynomial describe the influence of superplasticizer content. The application of SP and MK may produce cement-water suspensions with waterretaining capacity at $50-70 \%$ higher than control suspensions. The investigation of initial structure forming of cement pastes with SP-MK composite admixture indicates the extension of coagulation structure forming phase comparing to the pastes without additives. Crystallization stage was characterized by more intensive strengthening of the paste with SP-MK admixture comparing to the paste without admixtures and paste with SP. Results on the porosity parameters for hardened cement paste indicate a decrease in the average diameter of pores and refinement of pore structure in the presence of metakaolin. A finer pore structure associated with an increase in strength. X-ray analysis data reveal a growing number of small-crystalline low-alkaline calcium hydrosilicates and reducing portlandite content, when MK dosage increases. Scanning electron microscopy (SEM) data confirm, that hardened cement paste containing MK has crystalline structure with dominance of partially crystalized hydrosilicates and gel-like formations.
\end{abstract}

\section{Introduction}

Metakaolin (MK), a pozzolanic admixture of $\mathrm{N}$ type [1] consists mostly of amorphous aluminosilicate, obtained by firing kaolin clays with subsequent grinding. One of the common area of its application in construction is high-performance concrete, self-compacting concrete [2-5]. Self-compacting high-strength concrete is characterized by basal structure with 'floating' aggregate particles. In such a structure, grains of aggregate are considerably separated and almost do not interact with each other. Thus, properties of fresh and hardened concrete depend on the rheological, structural and mechanical properties of the cement-matrix.

Incorporation of $\mathrm{MK}$ as partial replacement of cement leads to significant changes in chemical composition and pore size distribution [6]. Studying of poor Greek Kaolin clays proved positive effect on the cement strength in different age of hardening. However, water demand increased significantly. The $\mathrm{Ca}(\mathrm{OH})_{2}$ content of is decreases from 7 and 28 days. MK content of $10 \%$ is considered the optimal replacement [7].

Replacement of Portland cement (PC) by MK up to $20 \%$ elongates the initial and final setting times of cement pastes due to coating effect of $\mathrm{MK}$ particles on the cement grains [8].

The rheology parameters of cement grouts containing MK, viscosity-modifying admixtures and polycarboxylate superplasticizer proved that MK reduces fluidity and increases yield stress and plastic viscosity [9].

The studying of Portlandite consumption in cement paste with metakaolin addition from 0 to $15 \%$ at constant water-binder ratio of 0.55 by thermogravimetric analysis proved that maximum removal due to pozzolanic reaction occurs at the ages of 14 days during the 365 days period 
of research. This corresponded to the maximum value of relative strength. After the age of 14 days, the reaction retarded [10].

MK adding proved to lead to refinement of the pores at the same water-binder. The proportion of pores with radii smaller than $20 \mathrm{~nm}$ increased as the level of PC with MK increased [11].

Most of the researches on cement pastes do not consider mutual influence of $\mathrm{MK}$ and superplasticizer (SP). However, the presence of SP at subsequent water demand reduction permits to create "tight" conditions of hydration. There is limited information about the properties of cement pastes with equal flowability.

\section{Aim and scope of the research}

The aim of the research was studying fresh and hardened cement paste properties with metakaolin in superplasticizer as if in this combination they usually applied in concrete.

There have been investigated the peculiarities of hydration and early structure formation.

The research was conducted in three main stages:

1 - studying of hydration processes at mixing with water: determination of water consumption (normal consistency) and water retention;

2 - studying of initial structural formation of pastes at setting and early age of hardening;

3 - studying of hydration and chemical composition of hardened cement pastes.

\section{Materials and methods applied}

The materials were used as follows. Locally produced PC CEMI 42,5, DIN 1146, EN-196 was used. The properties of cement are given in Tab. 1 and 2.

Table 1. Physical-mechanical properties of cement

\begin{tabular}{|c|l|c|}
\hline No. & \multicolumn{1}{|c|}{ Property, units } & Value \\
\hline 1 & $\begin{array}{l}\text { Fineness (008 sieve fraction } \\
\text { content), \% }\end{array}$ & 5 \\
\hline 2 & Specific surface by Blaine, $\mathrm{cm}^{2} / \mathrm{g}$ & 3,300 \\
\hline 3 & Normal consistency, \% & $24 \%$ \\
\hline 4 & $\begin{array}{l}\text { Hardening } \\
\text { - begins at }\end{array}$ & $\begin{array}{l}1 \mathrm{~h} 35 \mathrm{~min} \\
3 \mathrm{~h} 45 \mathrm{~min}\end{array}$ \\
\hline 5 & - ends at & $\begin{array}{c}\text { Meets the } \\
\text { requirements }\end{array}$ \\
\hline 6 & Uniformity of volume change & 8.75 \\
& - flexural & 54.0 \\
\hline 7 & - compressive & 3.5 \\
\hline
\end{tabular}

Superplasticizer (SP) of naphthalene formaldehyde type, high range water reducers - admixtures of $F$ type [12].

The properties of metakaolin are given in Tab.3 and 4.

Content of SP and MK was calculated as \% of binder weight $(\mathrm{PC}+\mathrm{MK}+\mathrm{SP})$. SP content varied in the range of 0 $-1.5 \%$, MK content $-0-15 \%$.
Table 2. Chemical composition of cement, $\%$ by weight

\begin{tabular}{|c|c|c|}
\hline No. & Composition & Value \\
\hline 1 & $\mathrm{CaO}$ & 67.15 \\
\hline 2 & $\mathrm{SiO}_{2}$ & 21.70 \\
\hline 3 & $\mathrm{Al}_{2} \mathrm{O}_{3}$ & 5.36 \\
\hline 4 & $\mathrm{Fe}_{2} \mathrm{O}_{3}$ & 4.10 \\
\hline 5 & $\mathrm{FeO}$ & - \\
\hline 6 & $\mathrm{MgO}$ & 0.74 \\
\hline 7 & $\mathrm{Cl}$ - ion content & - \\
\hline 8 & Loss on ignition & 0.34 \\
\hline 9 & Insoluble residue & 0.28 \\
\hline
\end{tabular}

Table 3. Chemical composition of metakaolin, $\%$ by weight

\begin{tabular}{|c|c|c|c|c|c|c|c|c|c|}
\hline $\mathrm{SiO}_{2}$ & $\mathrm{Al}_{2} \mathrm{O}_{3}$ & $\mathrm{Fe}_{2} \mathrm{O}_{3}$ & $\mathrm{TiO}_{2}$ & $\mathrm{CaO}$ & $\mathrm{MgO}$ & $\mathrm{MnO}$ & $\mathrm{Na}_{2} \mathrm{O}$ & $\mathrm{K}_{2} \mathrm{O}$ & L.O.I. \\
\hline 52.5 & 42.20 & 0.34 & 0.70 & 0.30 & 0.25 & 0.01 & 0.10 & 0.90 & 0.50 \\
\hline
\end{tabular}

Table 4. Physical and chemical properties of metakaolin

\begin{tabular}{|c|c|c|}
\hline No. & Property, units & Value \\
\hline 1 & Specific surface by Blaine, $\mathrm{cm}^{2} / \mathrm{g}$ & 18,000 \\
\hline 2 & Density, $\mathrm{g} / \mathrm{cm}^{3}$ & 2.50 \\
\hline 3 & Bulk density, $\mathrm{kg} / \mathrm{m}^{3}$ & 350 \\
\hline 4 & $\begin{array}{c}\text { Pozzolanic activity, } \mathrm{mg} / \mathrm{g}(\text { by } \mathrm{CaO} \\
\text { absorption) }\end{array}$ & 25 \\
\hline 5 & Normal consistency of metakaolin paste, $\%$ & 46 \\
\hline
\end{tabular}

There was tested normal consistency, water retention, setting time, water absorption according to standard methods. The other methods used are described in relevant parts of the article.

For each composition, the tests were conducted two times.

The adequacy of equations obtained was checked by calculating the adequacy dispersion, the design value of Fisher's criterion $\left(F_{d}-\right.$ criterion) [13] and comparing the last with a theoretical one $F_{t}$. The regression equation is adequate for the given probability level if $\mathrm{F}_{\mathrm{d}}<\mathrm{F}_{\mathrm{t}}$.

\section{Normal consistency and water retention of cement pastes}

Water consumption of the cement pastes is determined by their normal consistency and homogeneity.

Normal consistency is an important indicator of the physical characteristics of the cement paste. It has linear dependence on ultimate water retention and depends on cement composition and dispersion, as well as the type and quantity of additives.

To determine the impact of composite admixture of superplasticizer and metakaolin on normal consistency and water retention of pastes, experiments were performed two times for each composition. Compositions of paste and mean values of normal consistency are presented in Table 5. 
Table 5. Cement pastes compositions and normal consistency

\begin{tabular}{|c|c|c|c|c|}
\hline \multirow[b]{2}{*}{ \# } & \multirow{2}{*}{$\begin{array}{c}\text { SP, \% of } \\
\text { binder } \\
\text { weight }\end{array}$} & \multirow{2}{*}{$\begin{array}{c}\text { MK, } \\
\text { \% of binder } \\
\text { content }\end{array}$} & \multicolumn{2}{|c|}{ Normal consistency (NC), \% } \\
\hline & & & $\begin{array}{c}\text { experimental } \\
\text { value }\end{array}$ & $\begin{array}{l}\text { calculated } \\
\text { value }\end{array}$ \\
\hline 1 & 0 & \multirow{4}{*}{0} & 0.240 & 0.240 \\
\hline 2 & 0.5 & & 0.216 & 0.216 \\
\hline 3 & 1.0 & & 0.197 & 0.197 \\
\hline 4 & 1.5 & & 0.185 & 0.184 \\
\hline 5 & 0 & \multirow{4}{*}{5} & 0.252 & 0.251 \\
\hline 6 & 0.5 & & 0.227 & 0.227 \\
\hline 7 & 1.0 & & 0.210 & 0.208 \\
\hline 8 & 1.5 & & 0.197 & 0.195 \\
\hline 9 & 0 & \multirow{4}{*}{10} & 0.262 & 0.262 \\
\hline 10 & 0.5 & & 0.239 & 0.238 \\
\hline 11 & 1.0 & & 0.223 & 0.219 \\
\hline 12 & 1.5 & & 0.206 & 0.206 \\
\hline 13 & 0 & \multirow{4}{*}{15} & 0.272 & 0.273 \\
\hline 14 & 0.5 & & 0.251 & 0.249 \\
\hline 15 & 1.0 & & 0.228 & 0.230 \\
\hline 16 & 1.5 & & 0.215 & 0.217 \\
\hline
\end{tabular}

Experimental data are approximated by the following equation:

$$
N C=\left(A \cdot_{1}^{2}-B \cdot X_{1}\right)+\left(N C^{0}+C \cdot X_{2} / 100\right)
$$

where $A, B$ - coefficients, determined by the type superplasticizer: for used SP: $A=0.011 ; B=0.053$;

$X_{1}-$ SP content, $\%$ by binder weight;

$N C_{0}$ - normal consistency of cement paste without additives, $N C^{0}=0.24$;

$X_{2}$ - metakaolin content, \% by binder weight;

$C$ - coefficient, $\mathrm{C}=N C_{\mathrm{MK}}-N C_{0}$, where $N C_{\mathrm{MK}}=0.46$ (see

Tab. 4, normal consistency of metakaolin paste):

$C=0.46-0.24=0.22$;

Eq. (1) is adequate at $95 \%$ confidence probability:

$F_{d}=2.03<F_{t}=2.46$.

Fig. 1 demonstrates the influence of MK and SP content on normal consistency. As it can be seen from eq.(1) and Fig. 1, the dependence of NC on SP content is can be approximated by parabola, which means that effectiveness of SP decreases as its content grows. It corresponds to known experimental data related to silica fume [14]. Effect of metakaolin is linear and does not depend on the SP content. According to Akhverdov [15], the minimum amount of water required for the formation of coagulation structures in cement paste, is as follows:

$N C^{\min }=0.876 N C$

When water content is equal to $\mathrm{NC}$, water is contained mainly in solvate shells. As follows from Tab.5 and Fig. 1 when SP is added water consumption can be less than $N C^{\mathrm{min}}$. At this case effect of dilution caused by the action of SP leads to significant reduction in the thickness of the solvate shells and the formation of additional quantities of free water. NC of cement paste with SP is close to theoretical $\mathrm{W} / \mathrm{C}$, required for the hydration, which is $0.21 \ldots 0.23$ [16]. Introduction of MK which has a higher normal consistency than cement (see Tab. 4), leads to regular growth of water demand of cement paste and decreasing of water-reducing effect of SP. However, as shown in Fig. 1, the introduction of high dosages of SP (1 ... 1.5\%) with MK leads to appreciable water content reduction compared to cement paste without additives. Replacing $5 \%$ of $\mathrm{PC}$ by $\mathrm{MK}$ at $\mathrm{SP}=1.5 \%$, decreases normal consistency at $20 \%$, for replacing $\mathrm{PC}$ with $15 \%$ of $\mathrm{MK}$ water reduction is $10 \%$.

Water-binder ratio (W/B), which corresponds to ultimate water retaining capacity of paste is from $1.60 \cdot \mathrm{NC}$ to $1.65 \cdot \mathrm{NC}$. However, considering some possible vibrations at transportation it is considered from $1.30 \cdot \mathrm{NC}$ to $1.35 \cdot \mathrm{NC}[17,18]$.

There was determined influence of MK and SP on water-retaining capacity of cement suspensions.

There was determined water bleeding coefficient $\left(\mathrm{K}_{\mathrm{b}}\right.$, $\%$ ) of cement suspensions with the SP and MK at waterbinder ratio $(\mathrm{W} / \mathrm{B})$ equal to $1 . \mathrm{K}_{\mathrm{b}}$ represents the volume of water separated:

$$
K_{b}=\frac{a-b}{a} \cdot 100
$$

where a is an initial volume of cement suspension $\mathrm{cm}^{3}$; $\mathrm{b}$ is the volume of cement of settled suspension, $\mathrm{cm}^{3}$; Then the water-retaining capacity suspensions is as follows

$W R=1-K_{\mathrm{b}}$

WR, divided by 100 , is W/B of settled suspension. Mean values of bleeding coefficients and water-retaining capacity is shown in Tab. 6 .

Table 6. Water bleeding coefficient and water retaining

\begin{tabular}{|c|c|c|c|c|c|c|c|c|c|c|c|}
\hline \multirow{3}{*}{$\#$} & & & \multirow{2}{*}{\multicolumn{9}{|c|}{$\begin{array}{c}\text { Water bleeding coefficient, \% } \\
\text { Water retaining capacity, \% } \\
\text { after, hours }\end{array}$}} \\
\hline & \multirow[t]{2}{*}{$\begin{array}{c}\text { SP, } \\
\%\end{array}$} & \multirow[t]{2}{*}{$\begin{array}{c}\text { МTK } \\
\%\end{array}$} & & & & & & & & & \\
\hline & & & 0 & 0.5 & 1 & 1.5 & 2 & 2.5 & 3 & 3.5 & 4 \\
\hline \multirow{2}{*}{1} & 0 & 0 & $\underline{0}$ & 25.4 & 36.8 & 41.9 & 44.2 & 45.2 & 45.6 & 45.8 & 45.9 \\
\hline & 0 & 0 & 100 & 74.6 & 63.2 & 58.1 & 55.8 & 54.8 & 54.4 & 54.2 & 54.1 \\
\hline \multirow{2}{*}{2} & 0 & 10 & $\underline{0}$ & 13.2 & $\underline{19.0}$ & 22.0 & 23.9 & 25.5 & 25.9 & 25.9 & \\
\hline & 0 & 10 & 100 & 86.8 & 81.0 & 78.0 & 76.1 & 74.5 & 74.1 & 74.1 & \\
\hline \multirow[b]{2}{*}{3} & & & $\underline{0}$ & 17.6 & 25.5 & 29.0 & 30.0 & 31.1 & 32.0 & 32.4 & 32.5 \\
\hline & 0.5 & 10 & 100 & 82.4 & 74.5 & $\overline{71.0}$ & $\overline{70.0}$ & 68.9 & 68.0 & 67.6 & 67.5 \\
\hline \multirow{2}{*}{4} & 1 & 10 & $\underline{0}$ & 21.0 & 30.0 & 35,2 & 37,8 & 38,0 & 38,7 & 39.4 & 39.5 \\
\hline & & & 100 & 79.0 & 70.0 & 64,8 & 62,2 & 62,0 & 61,3 & 60.6 & 60 \\
\hline \multirow{2}{*}{5} & & 10 & $\underline{0}$ & 23.5 & 34.5 & 41,6 & 43,8 & 44,0 & 45,5 & 45.6 & 45,7 \\
\hline & 1.5 & & 100 & $\overline{76.5}$ & 65.5 & $\overline{58,4}$ & $\overline{56,2}$ & $\overline{56,0}$ & $\overline{54,5}$ & $\overline{54,4}$ & $\overline{54,3}$ \\
\hline \multirow{2}{*}{6} & 1 & 0 & $\underline{0}$ & 30.0 & 45.7 & 54.5 & 56.0 & 57.5 & 58.9 & 58.9 & \\
\hline & 1 & 0 & 100 & 70.0 & 54.3 & 45,5 & 44,0 & 42,5 & 41,1 & 41.1 & \\
\hline \multirow{2}{*}{7} & & & $\underline{0}$ & 25.0 & 38.5 & 43.0 & 47.0 & 48.5 & 48.8 & 48.9 & 49.0 \\
\hline & 1 & 5 & 100 & $\overline{75.0}$ & 61.5 & 57.0 & 53.0 & $\overline{51.5}$ & 51.2 & 51.1 & $\overline{51.0}$ \\
\hline \multirow{2}{*}{8} & 1 & 10 & $\underline{0}$ & 19.0 & 30.0 & 34.5 & 38.0 & 38.3 & 38.9 & 39.0 & \\
\hline & 1 & 10 & 100 & 81.0 & 70.0 & & 62.0 & 61.7 & 61.1 & 61.0 & \\
\hline \multirow{2}{*}{9} & 1 & 15 & $\underline{0}$ & 14.5 & 24.0 & 25.5 & 27.0 & 28.5 & 28.8 & 28.9 & \\
\hline & 1 & 15 & 100 & 85.5 & 76.0 & 74.5 & 73.0 & 71. & 71.2 & 71.1 & \\
\hline
\end{tabular}
capacity of cement suspensions

The influence of water retention on time of settlement can be described by the hyperbola dependence with horizontal asymptote as following 


$$
W R=100-\left(A+B X_{1}+C X_{2}\right) \cdot\left(1-1 / D^{\mathrm{t}}\right),
$$

where $X_{1}-$ SP content, $\%$ binder weight; $X_{2}-$ MTK content, $\%$ binder weight; $\mathrm{t}$ - time of sedimentation, $\mathrm{h} ; A$, $B, C$ and $D$ are coefficients, which depend on properties of materials applied (MK, SP); in current research: $A=46$; $B=13 ; C=-2 ; D=5$.

Eq. (5) is adequate at $95 \%$ confidence probability: $F_{d}=1.35<F_{t}=1.36$.

Fig. 2 shows dependencies of water retaining capacity on the SP and MK content. With increasing SP content ordinate asymptote decreases (Fig. 2 a); as MK dosage increases - ordinate asymptote increases too. (Fig. 2 b). The second part of the equation describes the dependence of water-retaining capacity on the time.

As time of settlement of suspension grows, water retaining capacity reduces close to asymptote. The presence of MK reduces bleeding of suspension due to higher sedimental stability of smaller particles of MK comparing to Portland cement.

According to the data Tab. 6, the use of additives SP and $\mathrm{MK}$, allows to obtain at the end of experiment suspensions with $\mathrm{WR}=(2.5-3) \cdot \mathrm{NC}$. At the same time, the control suspension without additives at the end of the experiment has $\mathrm{WR} \approx 2 \mathrm{NC}$, that value is close to the theoretical limit of water-retaining capacity of cement (upper limit of thixotropy) [14]. That is caused by higher water demand of MK comparing to PC.

Thee water-retaining capacity of suspensions made with binders of equal water consumption was compared.
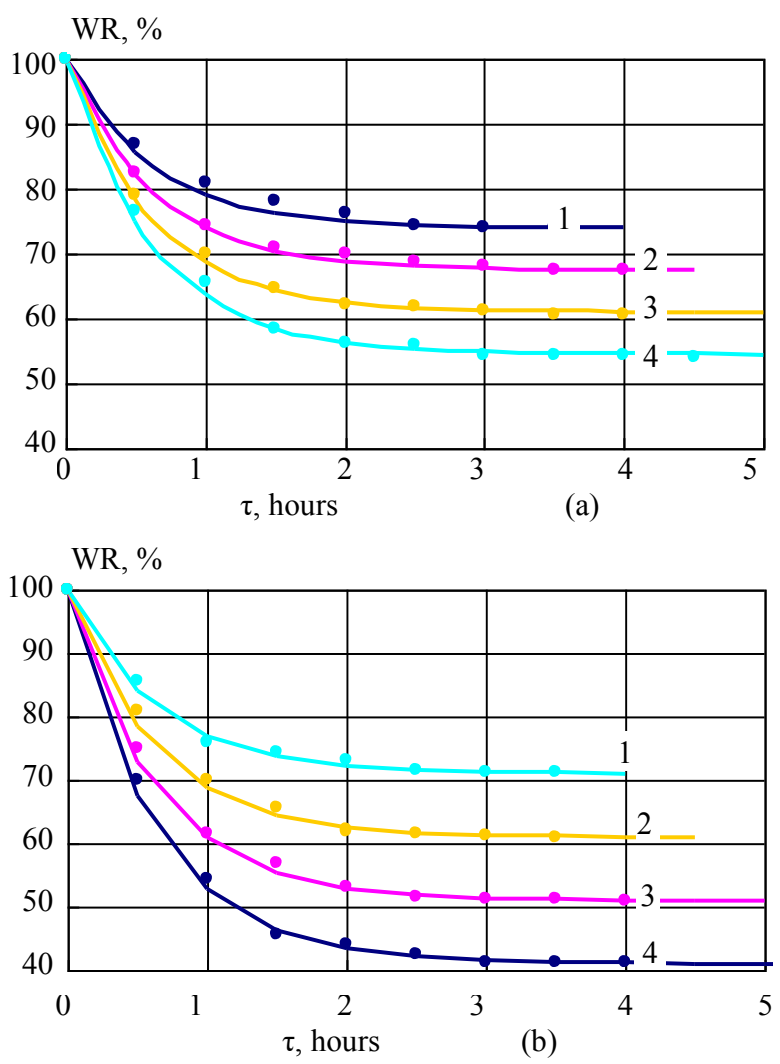

Fig. 2. Kinetics of water retaining of cement suspensions: a) at $\mathrm{MK}=10 \%, 1-\mathrm{SP}=0 \%, 2-\mathrm{SP}=0.5 \%, 3-\mathrm{SP}=1 \%$, $4-\mathrm{SP}=1.5 \%$

b) at $\mathrm{SP}=1 \%, \mathrm{MK}=15 \%, \mathrm{MK}=10 \%, \mathrm{MK}=5 \%$
It was assigned $\mathrm{NC}=0.24$ (as for control composition). Varying MK content from 5 to $15 \%$, SP content was calculated according to formula (1). According to formula (4) the water retention was determined. The results are shown in Fig. 3.

As it can be seen increasing of MK content at substantial SP dosage increase leads to significant growth of water retaining capacity. At replacing $5 \%$ of PC by $\mathrm{MK} \mathrm{WR}=61.3 \% \quad(\mathrm{~W} / \mathrm{B}=0.613)$, at $15 \%-\mathrm{WR}=74.7 \%$ $(\mathrm{W} / \mathrm{B}=0.747)$.

WR, \%

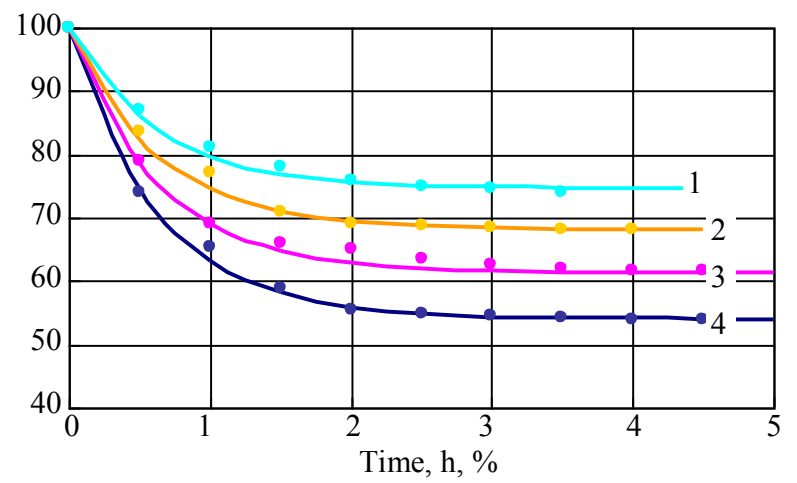

Fig. 3. Kinetics of water retaining of cement suspensions with equal normal consistency $24 \%$ calculated by formula (4): $1-\mathrm{SP}=0.72 \%, \mathrm{MK}=15 \% ; 2-\mathrm{SP}=0.45 \%, \mathrm{MK}=10 \%$; $3-\mathrm{SP}=0.21 \%, \mathrm{MK}=5 \% ; 4-\mathrm{SP}=0 \%, \mathrm{MK}=0 \%$

In the case of self-compacting high-strength concrete $\mathrm{W} / \mathrm{C}$ is normally lower than 0.4. Taking into consideration water consumption of fine and coarse aggregate for their moistening, actual W/C of cement paste in concrete is within the range 0.25-0.35 [19]. Taking into consideration ultimate water retention of control cement paste water-binder ratio selected for further research was $W / B=1.35 N C^{0}=1.35 \cdot 0.24=0.33(5)$.

\section{Peculiarities of initial structure forming of cement pastes}

The flowability of the pastes tested in the research was determined by the flow spread diameter of the Vicat apparatus cone (upper $\varnothing 70 \mathrm{~mm}$, bottom $\varnothing 100 \mathrm{~mm}$, $\mathrm{h}=40 \mathrm{~mm})$. The diameter of paste was assigned for compositions \#2-5 as $(200 \pm 1) \mathrm{cm}$. In this case we received self-levering paste like that in self-compacting concrete. The compositions are shown in Tab. 7.

Table 7. Cement pastes compositions

\begin{tabular}{|c|c|c|c|c|c|}
\hline \# & \multirow{2}{*}{ W/B } & $\begin{array}{c}\text { Flow } \\
\text { spread } \\
\text { diameter, } \\
\text { mm }\end{array}$ & $\begin{array}{c}\text { MK, \% } \\
\text { by binder } \\
\text { weight }\end{array}$ & $\begin{array}{c}\text { SP, \% by } \\
\text { binder } \\
\text { weight }\end{array}$ & $\begin{array}{c}\text { NC } \\
\text { (according } \\
\text { to formula } \\
(1))\end{array}$ \\
\hline 1 & \multirow{5nnyyy}{*}{0.33} & 100 & 0 & 0 & 0.240 \\
\cline { 4 - 6 } & & 0 & 0.32 & 0.224 \\
\hline 4 & \multirow{2}{*}{200} & 5 & 0.46 & 0.229 \\
\cline { 4 - 6 } & & 10 & 0.64 & 0.232 \\
\cline { 4 - 6 } & & 15 & 0.95 & 0.233 \\
\hline
\end{tabular}


For determination of initial structure formation of cement paste there were used standard setting time test and ultrasonic pulse velocity. Comparing setting time of the compositions is shown in Tab 8.

Table 8. Setting time of cement pastes according to Vicat apparatus and ultrasonic pulse velocity test

\begin{tabular}{|c|c|c|c|c|c|c|}
\hline \multirow{2}{*}{$\#$} & \multirow{2}{*}{$\begin{array}{c}\text { NC, } \\
\%\end{array}$} & \multicolumn{4}{|c|}{$\begin{array}{c}\text { Setting time (Vicat apparatus), } \\
\text { h-min }\end{array}$} & $\begin{array}{c}\text { Setting time } \\
\text { by ultrasonic } \\
\text { pulse velocity } \\
\text { test }\end{array}$ \\
\cline { 3 - 7 } & & initial & final & initial & final & initial \\
\hline 1 & 24.0 & $1-35$ & $3-45$ & $4-25$ & $6-45$ & $4-00$ \\
\hline 2 & 22.4 & $3-15$ & $4-35$ & $6-30$ & $7-50$ & $6-10$ \\
\hline 3 & 22.9 & $1-25$ & $4-20$ & $4-40$ & $8-00$ & $4-30$ \\
\hline 4 & 23.2 & $1-45$ & $4-35$ & $4-50$ & $8-25$ & $4-25$ \\
\hline 5 & 23.3 & $2-15$ & $4-55$ & $5-00$ & $8-40$ & $4-50$ \\
\hline
\end{tabular}

As cement had relatively low-volume of $\mathrm{C}_{3} \mathrm{~A}, \mathrm{SP}$ do not adsorb intensively by aluminates. Therefore, SP retards setting of cement paste due to lower thickness of the solvate shells comparing to high-alumina cements and releasing of additional mixing water. The water can adsorb both at the grains of unhydrated cement and hydrated new formations. At adsorption, diffusive resistance increases and dissolution of cement grains inhibits $[14,19]$. At MK addition and SP there is a "tight" hydration conditions [20] there is close contact between the solid particles due to the increase of its concentration and higher surface area of MK. Because of the increase of physically and chemically bound water, the thickness of water interlayers reduces. This leads to acceleration of initial setting time. With time, the intensity of new formations growth reduces, and the final setting time of pastes \#3-5 is close to paste \#2. As MK content increases, structure forming processes of paste retards due to adsorption of SP on particles of MK and blocking of cement hydration. Similar phenomena are observed for pastes with $\mathrm{W} / \mathrm{B}=0.33$. However, because of their higher water content, processes initial structure forming retard at 3-5h (Tab 8).

The ultrasonic velocity can determine the end time of inductive stage in structure formation after mixing with water [21], which corresponds to initial setting time. The method of through passage of longitudinal ultrasonic pulse was used during $24 \mathrm{~h}$ with measuring each $30 \mathrm{~min}$. Results of the test are given in Tab. 8 and Fig. 4 (for compositions \#1, 2 and 4, W/B=0.33).

As shown in the Fig. 4, curves of ultrasonic pulse velocity have sections, which correspond to the stages of structure forming. At the initial stage (the inductive period) C slightly increases (marked as horizontal section). Subsequent formation of low-strength crystallization structure of aluminate components significantly affects $\mathrm{C}: \mathrm{dC} / \mathrm{d} \tau$ is maximum at this stage. At the stage of silicates crystallization, which are the main carriers of strength, the rate of velocity growth reduces.

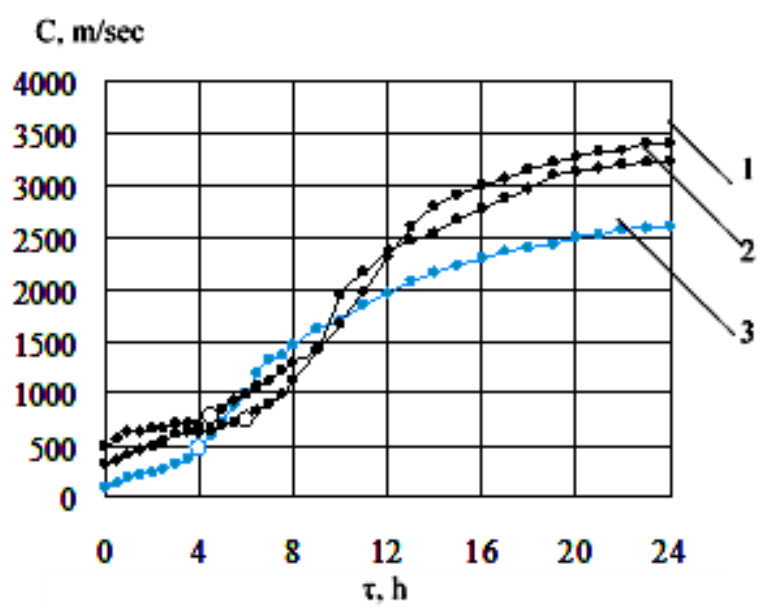

Fig. 4. Ultrasonic pulse velocity at early structure formation of cement pastes:

$1-\mathrm{SP}=0.64 \%, \mathrm{MK}=10 \% ; 2-\mathrm{SP}=0.32 \% 3-$ control

The initial stage of coagulation structure forming is characterized by horizontal sections, which ends by inflection point (white point). It corresponds to the initial setting time. Growth of MK content leads to intensifying of the ultrasonic pulse passage.

This research method is more informative for initial structure forming than setting time test. Setting time test permits to estimate the period of coagulation. Whereas ultrasonic pulse velocity test - to estimate the physical and chemical changes that lead to the formation of microstructure of the pastes. However, the values of initial setting time determined by these both methods are correlated with each other. The introduction of the SP and MK retards initial structure formation due to the of adsorptive films of SP, which prevent hydration.

Crystallization structure stage is characterized by intensive strengthening of paste with SP and MK due to the active binding of portlandite with metakaolin and the formation of additional quantities of stable low-basic crystalline hydrate CSH (I). For more detailed testing of structure formation processes X-ray SEM analysis were applied.

\section{Peculiarities of structure of hardened cement paste}

There were determined influence of MK and SP on porous structure of cement paste and its phase composition. To provide uniformity and compatibility of output parameters all the pastes had equal consistency (flow spread diameter $200 \mathrm{~mm}$ ) and $\mathrm{W} / \mathrm{B}=0.33$.

The peculiarities of the modification of cement paste with MK and SP additions is determined by the parameters of its pore structure. One of the most simple and universal methods of investigation pore structure of cement is water absorption method [22], which allows to determine how integrated (apparent porosity) and differential parameters of pore structure (the average pore size and uniformity of their size).

Numerous experiments of water absorption of multicapillary materials such as cement stone and concrete, can be described by exponential function. In general, water absorption curves of cement pastes are 
approximated by three-parameter exponential function of the form:

$W_{\tau}=W_{\max }\left(1-e^{-\lambda \cdot \tau^{\alpha}}\right)$

where $\mathrm{W}_{\tau}$ is water absorption after $\tau$ hours, $\% ; \mathrm{W}_{\max }-$ conventional value of maximum water absorption, $\% ; \lambda-$ coefficient, which determines average diameter of capillary pores; $\alpha$ - coefficient, which determines uniformity of capillaries size; $\tau$ - time of saturation of specimen, $\mathrm{h}$.

For determination of porosity paraments according to kinetics of water absorption cubic specimens with $7 \mathrm{~cm}$ sedge were prepared. After curing at normal hardening chamber for 28 days, the specimens were dried at $\mathrm{t}=105 \ldots 110^{\circ} \mathrm{C}$. The water absorption was determined during $2 \mathrm{~h}$ after saturation and in $24 \mathrm{~h}$ of saturation, (which corresponds to conventional total open porosity). Kinetics of water absorption is shown on Fig. 5.

For all the pastes (see Tab. 7) Eq. 6 is adequate at 95\% confidence probability: composition \#1: $F_{d}=1.94<F_{t}=4.19$;

$\# 3: F_{d}=2,05<F_{t}=4,53$; $\# 2: F_{d}=1,77<F_{t}=4,19$; $\# 5: F d=1,83<F_{t}=4,1$. $\# 4: F_{d}=1,66<F_{t}=3,84$;

There was determined weight water absorption, \%:

$W_{m}=\frac{m_{24}-m_{0}}{m_{0}} \cdot 100$,

And volumetric water absorption, \% (open porosity):

$W_{0}=\frac{m_{24}-m_{0}}{m_{24}-m_{24}^{B}} \cdot 100$,

where $m_{0}$ is a mass of the specimen in dry state (weight in air), $\mathrm{kg} ; m_{24}$ is a mass of specimen after $24 \mathrm{~h}$ of saturation (weight in air), $\mathrm{kg} ; m^{w}{ }_{24}$ is a mass of specimen after $24 \mathrm{~h}$ of saturation, (weight in the water) $\mathrm{kg}$.

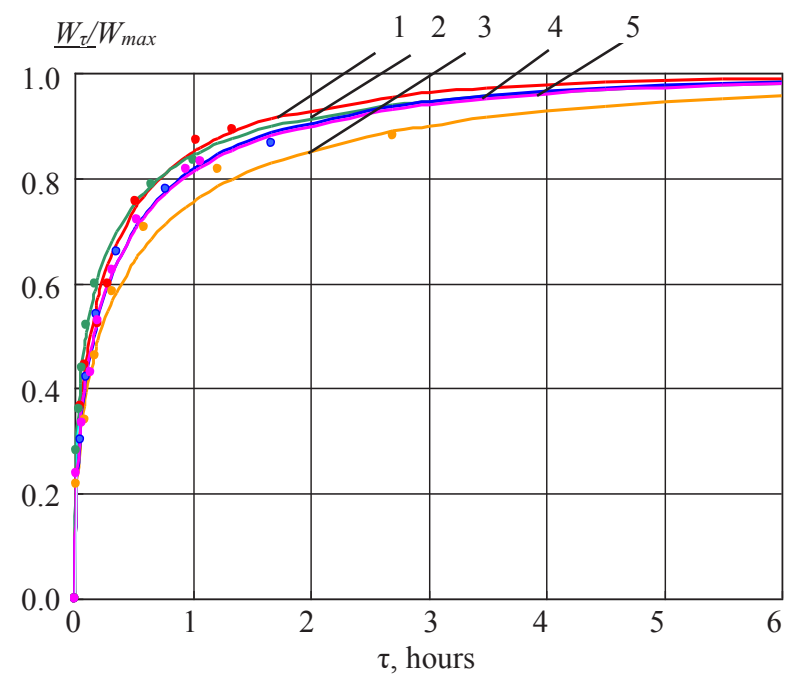

Fig. 5. Kinetics of water absorption of cement paste: $1-\mathrm{MK}=0 \%, \mathrm{SP}=0 \% ; 2-\mathrm{MK}=0 \%, \mathrm{SP}=0.32 \%$; $3-\mathrm{MK}=5 \%, \mathrm{SP}=0.46 \% ; 4-\mathrm{MK}=10 \%, \mathrm{SP}=0.64 \%$; $5-\mathrm{MK}=15 \%, \mathrm{SP}=0.95 \%$

As it can be sen from the Tab. 9, the growth of MK content in binder leads to reduction of average diamenter of pores (coefficient $\lambda$ ) and increasing their uniformity (coefficient $\alpha$ ). Water absorption and open prosity reduces.

Table 9. Parameters of porous structure of cement paste

\begin{tabular}{|c|c|c|c|c|c|c|}
\hline$\#$ & SP, \% & $\begin{array}{c}\text { MTK, } \\
\%\end{array}$ & $\alpha$ & $\lambda$ & $\begin{array}{c}\text { Water } \\
\text { absorption } \\
\text { (mass) } \\
\mathrm{W}_{\mathrm{m}}, \%\end{array}$ & $\begin{array}{c}\text { Water } \\
\text { absorption } \\
\text { (volume) } \\
\mathrm{W}_{0}, \%\end{array}$ \\
\hline 1 & 0 & 0 & 0.494 & 1.889 & 9.80 & 19.39 \\
\hline 2 & 0,32 & 0 & 0.417 & 1.847 & 9.61 & 18.72 \\
\hline 3 & 0,46 & 5 & 0.491 & 1.690 & 7.44 & 14.55 \\
\hline 4 & 0,64 & 10 & 0.476 & 1.663 & 7.52 & 14.01 \\
\hline 5 & 0,95 & 15 & 0.451 & 1.401 & 7.06 & 13.20 \\
\hline
\end{tabular}

It confirms the data about formation of finecrystalline structure with prevalence of low-base calcium silicates $\mathrm{CSH}(\mathrm{I})$ [24]. In accordance to the general laws of structure formation [23], the introduction of ultra-fine materials leads to a change in the balance between the gel (and capillary pores in favor of the first and cement structure is more dispersed.

There were conducted X-ray and SEM study of cement at the age of 28 days, at early stages of structure formation with the addition of ultrafine reactive materials "physical factor" dominates, which " fill the volume between coarse particles of cement and form numerous low-strength coagulation contacts" [24]. "Chemical factor", which is expressed in changing the balance of hydration new formations to growth of number of stronger and more stable compounds, has significant value in later ages of hardening.
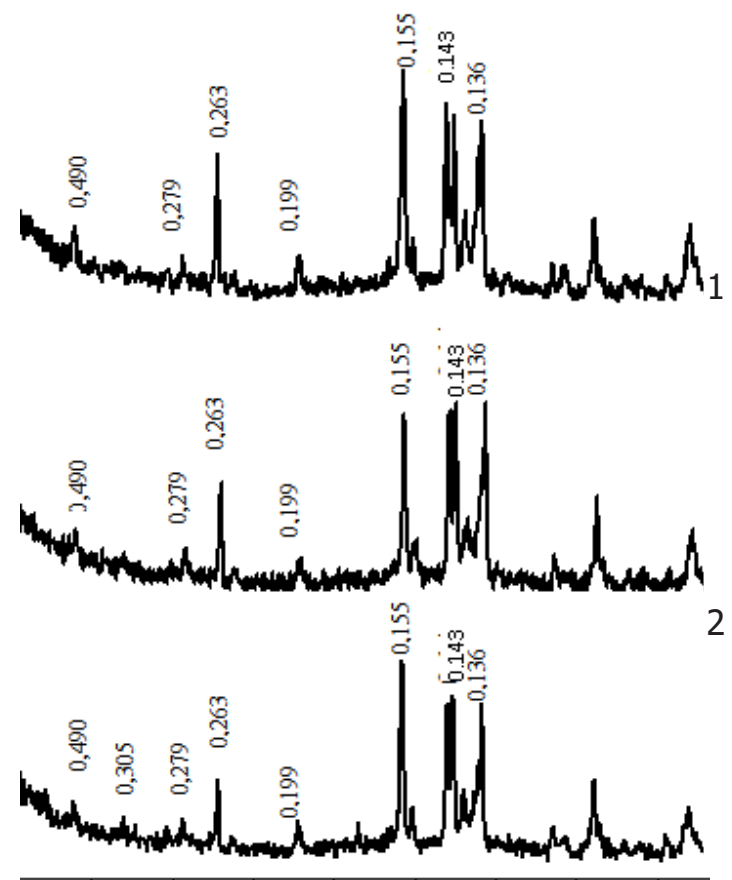

$\begin{array}{llllllll}10 & 15 & 20 & 25 & 30 & 35 & 40 & 45\end{array}$ $2 \theta$

Fig. 6. X-ray of cement stone at the age of 28 days: $1-\mathrm{MK}=0 \%, \mathrm{SP}=0.32 \% ; 2-\mathrm{MK}=5 \%, \mathrm{SP}=0.46 \%$; $3-\mathrm{MK}=10 \%, \mathrm{SP}=0.64 \%$ 

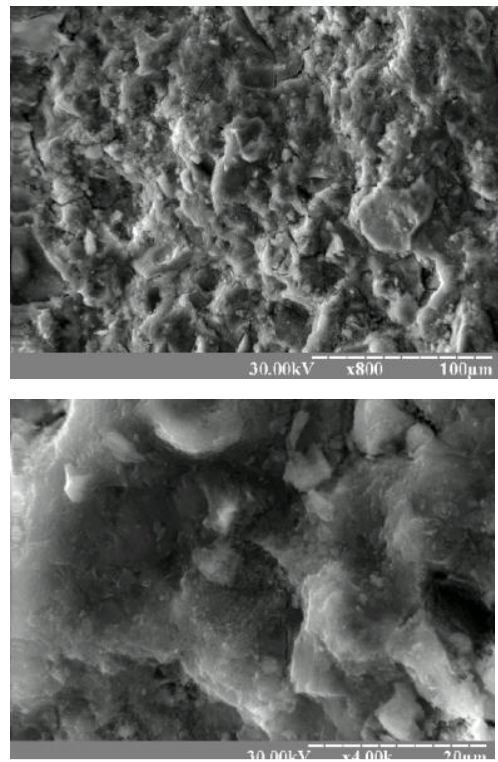

Fig. 7. Microstructure of cement stone: $\mathrm{SP}=0.64 \%$; $\mathrm{MK}=10 \%$ (x800 upper, $\mathrm{x} 4000$ - bottom)

The results of X-ray analysis at the age of 28 days (Fig. 6) For all pastes indicate the presence of crystalline crystallized tobermorite-like calcium hydrosilicates $\mathrm{CSH}(\mathrm{I})$ with variable structure: $(1-1.5) \mathrm{CaO} \cdot \mathrm{SiO}_{2} \cdot \mathrm{H}_{2} \mathrm{O}$ $(\mathrm{d}=0,305 ; 0,279 ; \mathrm{nm})$. As the dosage of MK grows - the content of the minerals increases, as it can be seen from increased intensity of the diffraction peaks. Portlandite $\mathrm{Ca}(\mathrm{OH})_{2}$ content $(\mathrm{d}=0,490 ; 0,263 ; 0,143 \mathrm{~nm})$, decreases with increasing portion of MK. Small amount of ettringite $(\mathrm{d}=0,155 \mathrm{~nm})$ is present in both early and late terms of hardening, the content of it is proportional to the amount of metakaolin and tobermorite-like calcium hydrosilicate $\mathrm{CSH}$ (II) $2 \mathrm{CaO} \cdot \mathrm{SiO}_{2} \cdot \mathrm{H}_{2} \mathrm{O}(\mathrm{d}=0.199 \mathrm{~nm})$.

The results of SEM analysis of cement paste structure (Fig. 7) show dominance of fine crystalline hydrates and gel-like products. Overall cement structure is dispersed.

\section{Conclusions}

1. The following conclusions are based on the results of this investigation. The normal consistency depends on the content SP and MK, which indicates a positive linear relationship between the water demand increase and MK content growth. The influence of SP content is described by polynomial of the second degree that confirms reduction of SP efficiency superplasticizer when the content in the paste over $1 \ldots 1.5 \%$.

2. It is shown that the use of SP and MK allows to obtain cement suspensions with water-retaining capacity up to (2.5-3.0) $\mathrm{NC}$, while for the control suspension it is (1.65-1.75) NC. It is caused by high water-retaining ability of metakaolin.

3. The structure of cement pastes with admixtures show elongation of coagulation stage structure compared to control paste. Crystallization stage is characterized by more intensive strength growth of pastes with SP and MK comparing to that with SP indicated by ultrasonic pulse velocity.
4. There is a decrease in the total diameter pores and improve in their homogeneity when SP and MK are added.

5. X-ray data give evidence of the growing number of small-crystalline low-base calcium hydrosilicates and reduction of Portlandite in cement, at increasing the MK content. According to SEM analysis cement paste with SP and MK has crystalline structure that has fine crystalline structure with partly crystalized hydrosilicates and gel-like formations.

\section{References}

1. ASTM Standard C618-89a. Standard Specification for Coal Fly Ash and Raw or Calcined Natural Pozzolan for Use in Concrete.

2. S. Wild. J.M. Khatib..A. Jones. Relative strength, pozzolanic activity and cement hydration in superplasticised metakaolin concrete. Cement and Concrete Research. 26(10), October 1996, 1537-1544. https://doi.org/10.1016/0008-8846(96)00148-2

3. C.S. Poon, S.C. Kou, L. Lam. Compressive strength, chloride diffusivity and pore structure of high performance metakaolin and silica fume concrete. Construction and Building Materials. Volume 82, 1 May 2015, Pages 133141. https://doi.org/10.1016/j.conbuildmat.2005.07.001

4. Dvorkin L., Bezusyak A., N. Lushnikova, Ribakov Y. Using mathematical modeling for design of self compacting high strength concrete with metakaolin admixture. Construction and Building Materials. Volume 37, December 2012, Pages 851-864.

https://doi.org/10.1016/j.conbuildmat.2012.04.019

5. E.G. Badogiannis, I.P. Sfikas, D.V. Voukia, K.G. Trezos, S.G. Tsivilis. Durability of metakaolin Self-Compacting Concrete. Construction and Building Materials. Volume 82, 1 May 2015, Pages 133-141. https://doi.org/10.1016/j.conbuildmat.2015.02.023

6. N.L. Coleman, C.L.Page Aspects of the pore solution chemistry of hydrated cement pastes containing metakaolin. Cement and Concrete Research 27(1):147-154 - January 1997 DOI: 10.1016/S0008-8846(96)00184-6

7. E. Badogiannis, G. Kakali, G. Dimopoulou, E. Chaniotakis, S. Tsivilis. Metakaolin as a main cement constituent. Exploitation of poor Greek kaolins. Cement \& Concrete Composites 27 (2005) 197-203.

8. H. El-Diadamony, A.A. Amer, T.M. Sokkary, S.El-Hoseny. Hydration and characteristics of metakaolin pozzolanic cement pastes. HBRC Journal Available online 27 May 2016 In Press, https://doi.org/10.1016/j.hbrcj.2015.05.005

9. Influence of the type of viscosity-modifying admixtures and metakaolin on the rheology of grouts. M. Sonebi, W. Schmidt, J. Khatib Chemistry and Materials Research, Vol.5 2013. Special Issue for International Congress on Materia 1s \& Structural Stability, Rabat, Morocco, 27-30 November 2013.

10. S. Wild,.J.M. Khatib. Portlandite consumption in metakaolin cement pastes and mortars Cement and Concrete Research Volume 27, Issue 1, January 1997, Pages 137-146.

11. J.M. Khatib, S. Wild Pore size distribution of metakaolin paste. Cement and Concrete Research. Volume 26, Issue 10, October 1996, Pages 1545-1553.

12. ASTM C494 / C494M - 11. Standard Specification for Chemical Admixtures for Concrete.

13. Ž.R. Lazić. Design of experiments in chemical engineering: A practical guide. Weinheim: WILEY-VCH Verlag GmbH \& $\mathrm{Co}, \mathrm{KGaA} ; 2004$. 
14. V.G. Batrakov. Modified concrete. Theory and practice. 2nd edition, Moscow, 1998. $-768 \mathrm{p}$.

15. I.N. Akhverdov. Concrete Physics Fundamentals, Moscow, 1981. (in Russian)

16. O.P. Mchedlov-Petrossyan. Chemistry of non-organic building materials. - M.:Stroyizdat, 1988. - 304 p. (in Russian)

17. V.S. Demianova, V.I. Kalashnikov, I.E. Ilyina. Comparative estimation of the influence of local and abroad superplasticizers on the properties of cement compositions. // Strointelnye materialy (Building Materials). 2002 (9) 4-6. (in Russian)

18. V.R. Falikman, A.Y. Vainer, N.F. Bashlykov. New generation of superplasticizers. // Beton i Zhelezobeton (Concrete and Reinforced Concrete). 2000 (5).5-7. (in Russian)

19. V.P. Sizov. Strength of concrete based on low water demand binders. // Beton i Zhelezobeton (Concrete and Reinforced Concrete) 1990 (10) 14-15. (in Russian)

20. M.M. Sychev Perspectives of increasing of the strength of cement stone. // Cement, 1987 (9) 17-19. (in Russian)

21. Y. Lin, C.-P. Lai, and T. Yen. Prediction of Ultrasonic Pulse Velocity (UPV) in Concrete. Materials Journal. Volume: 100 Issue: 1: 21-28. (in Russian)

22. Sheikin, A.E. Structure and properties of cement concrete / A.E. Sheikin, Y.V. Chekhov, M.I. Brusser. - M.: Stroyizdat, 1979. - 344 p. (in Russian)

23. S.Kaprielov, A. Sheinfeld Influence of Silica Fume / Fly Ash / Superplasticizer Combinations in Powder-like Complex Modifiers on Cement Paste Porosity and Concrete Properties. //Sixth CANMET/ACI International Conference on Superplasticizers and other Chemical Admixtures in Concrete. Nice, France, October 2000. Proceedings, pp.383400.

24. Massazza F. Chemisry of pozzolanic admixtures and composite cements. // Proc. $7^{\text {th }}$ International congress of the chemistry of cements. Vol.3. - Mockow , 1976 - p. 209211. 